\title{
Meaning in family caregiving for people with dementia: a narrative study about relationships, values, and motivation, and how day care influences these factors
}

This article was published in the following Dove Press journal: Journal of Multidisciplinary Healthcare

\section{Signe Tretteteig ${ }^{1,2}$ \\ Solfrid Vatne ${ }^{3}$ \\ Anne Marie Mork \\ Rokstad ${ }^{1,3}$}

'Norwegian National Advisory Unit on Ageing and Health, Vestfold Hospital Trust, Tønsberg, Norway; ${ }^{2}$ Faculty of Medicine, University of Oslo; Oslo, Norway; ${ }^{3}$ Faculty of Health Sciences and Social Care, Molde University College, Molde, Norway
Correspondence: Signe Tretteteig Norwegian National Advisory Unit on Ageing and Health, Vestfold Hospital Trust, Taranrødveien 47, 317I SEM, Tønsberg, Norway

Email Signe.tretteteig@aldringoghelse.no
Background: In addition to care-related burdens, most caregivers of a person with dementia perceive a variety of positive and satisfying experiences, such as feeling needed and useful in their family caregiving role. "Meaning-focused coping" describes both positive and negative emotions in periods with high levels of stress. Day care service may have the potential to increase caregivers' positive experiences and meaning-focused coping, and positively influence interpersonal relationships between those giving care and those receiving care. The aim of this study was to gain knowledge about family caregivers' experiences of meaning in their caring role. Additionally, the influence of day care services on caregivers' experiences and motivation in their caregiving role is explored.

Methods: A qualitative design based on individual interviews was used. The interviews were analyzed using a narrative method and a case study approach.

Findings: Family caregivers' roles and coping strategies were related to their relational ties. Caregivers had to make decisions about whether to enhance, maintain, or let go of emotional ties to find a good balance between meeting their own needs and the needs of the person with dementia. Family caregivers reported that day care positively influenced their "relationshiporiented coping" and experience of meaning.

Conclusion: Finding meaning in the role of a family caregiver for persons with dementia is closely connected to the caregivers' own values and goals. Finding a balance between attending to their own needs and the needs of the person with dementia is crucial. Day care has the potential to increase family caregivers' motivation to care by supporting their capacity to meet their own needs, cooperate and communicate with the person with dementia, and make competent and autonomous choices, thus increasing their feeling of mastery.

Keywords: dementia, family caregivers, day care, meaning, values, relationship-oriented coping

\section{Introduction}

Dementia is one of the most challenging age-related illnesses, not only for those diagnosed with dementia but also for their family caregivers and health care professionals. ${ }^{1,2}$ The burdens associated with caring for people with dementia, including physical, psychological, social, and financial aspects, are well known. ${ }^{3,4}$ However, most caregivers also perceive a variety of positive and satisfying experiences of feeling needed and useful in their role. Much can be gained by examining the positive dimensions of caregiving, including experiences, appraisals, and emotions, and the strengths and resources that caregivers can call upon in managing the challenges they face. ${ }^{5}$ Posi- 
tive experiences are mainly associated with the way caring becomes meaningful. ${ }^{6}$ The concept of meaning-focused coping has been previously described in work on stress and coping theory. ${ }^{7-9}$ According to Folkman, meaningful coping can be described as appraisal-based coping in which a person draws on his or her values, beliefs, and existential goals to motivate and sustain coping and well-being during a difficult time. ${ }^{10}$ This concept has influenced research on the positive aspects of family caregiving. Caregivers describe both positive and negative emotions during periods with high levels of stress. Meaning-focused strategies and experiences of control are central to experiencing positive emotions during life challenges, and meaning-focused coping strategies have a positive influence on family caregivers' reappraisal of their situation. ${ }^{5,10}$ Knowledge about the variety of family caregivers' sources of motivation, the meaning of focus in their caregiving role, and their strategies to achieve this meaning will be useful for health care staff. Such knowledge will improve their ability to support family caregivers and enhance the underlying positive aspects of caregiving.

A central dimension of caregiving during the course of dementia is the need for caregivers to reappraise their relationship with the person with dementia. The term "relationship-oriented coping" is used to describe coping in spousal relationships. ${ }^{11,12}$ As sustained and robust relationships are central to the human experience, efforts should be invested in developing sensitive approaches to prevent or reduce caregiver burden. Molyneaux et $\mathrm{al}^{13}$ advocate the need to refocus attention on the quality of relationships and interactions between spouses when one partner acts as a caregiver for the other who has dementia. This renewed focus might be central to parent-child caregiver-patient relationships as well. Hence, the meaning of family caregiving should be explored in terms of experiences of living with people with dementia in the context of close interpersonal relationships.

In Norway, day care for people with dementia consists of adapted treatment provided during the daytime. ${ }^{14}$ The purpose of this care is to give people with dementia a meaningful everyday life in an environment focusing on social interaction, safety, and the experience of coping. ${ }^{15}$ Additionally, day care is meant to provide respite for family caregivers, help them cope with challenging everyday care situations, and motivate them to care. Combined with homebased care services, day care aims to postpone or eliminate the need for placement in an institution. ${ }^{16} \mathrm{~A}$ national survey from 2014 revealed that $73 \%$ of the municipalities in Norway offered day care designed for people with dementia. However, service utilization was low and opening hours were limited to an average of 20.5 hours per week distributed over 3.6 days. ${ }^{17}$

As a respite service, day care may have the potential to support family caregivers' relationship-oriented coping. Caregivers describe their role as complex, and the relief the day care service provides contributes to increasing their patience, their energy to cope with everyday challenges, and their ability to plan activities while considering the person with dementia. Furthermore, the experience of relief prevents conflicts and improves the quality of time caregivers spend with the person for whom they are caring. For example, the activities that individuals with dementia take part in at a day care center might positively influence their conversations with their family caregiver. Day care can increase relationship-oriented coping by helping caregivers maintain good relationships with friends and other family members. ${ }^{18,19}$

Based on theory and previous research, there are reasons to believe that family caregivers' positive experiences of meaning and coping are related to the extent to which they are able to act in accordance with their values, beliefs, and/or achieve their existential goals despite caring for someone with dementia. Furthermore, the interpersonal relationship between caregivers and people with dementia needs to be further explored.

The aim of this study was to gain knowledge about family caregivers' experiences of meaning in their caring role. Additionally, the influence of day care services on caregivers' experience and motivation in their caregiving role is explored.

\section{Methods}

This study has a qualitative design based on a narrative analysis ${ }^{20-22}$ using individual in-depth interviews. Based on the aim of this study, three research questions were formulated.

1. What motivates family caregivers to provide care?

2. How do family caregivers find meaning and develop a sense of coping in their role?

3. How does day care influence family caregivers' sense of coping and motivation in the role?

Narrative analysis allowed us to gain deeper insight into the everyday lives of family caregivers according to these research questions. Narrative studies rely on extended accounts that are preserved and treated analytically as units, rather than as fragments divided into thematic categories, as is customary in other forms of qualitative analysis. Each interview was therefore analyzed as a single unit, to highlight points that create context or breaks in the story more than to identify similarities and dissimilarities with the other stories. In a narrative study, attention shifts to the details - how 
and why a particular event is recounted, or what a narrator accomplishes by developing the story that way. In this study, narrative analysis provided greater scope for including and emphasizing past experiences and self-representation in the analysis, ${ }^{22}$ which was assumed to be an interesting dimension of how family caregivers experience their role.

According to Riessman, in a narrative inquiry, the analyst "is interested in how a speaker or writer assembles and sequences events and uses language and/or visual images to communicate meaning, that is, make particular points to an audience". ${ }^{22}$ Additionally, Riessman does not simply emphasize the content of the story, but also interrogates the storyteller's intentions: how do people choose to tell their stories and why. A narrative method with a performative analysis focuses on the identity or the character of the person who tells the story. In this study, we paid special attention to how the caregivers positioned themselves in relation to the person with dementia. ${ }^{23,24}$

The study is a part of the research project "Effects and costs of a day care centre program designed for people with dementia - a 24-month controlled study (ECOD)." ${ }^{25}$ This study has been accepted by the Regional Committee for Medical and Health Research Ethics for South East Norway, and the participants gave written informed consent. The participants in the current study were recruited from the intervention group in the ECOD study and selected to participate in this study based on the themes that were exposed during interviews, for example, their descriptions of their experience of meaning and other positive aspects of the caregiving role. To go into even more depth with these themes, these family caregivers were contacted again and invited to take part in this study. All the invited family caregivers agreed to take part in the study. As described in Table 1, the sample represented a variety of roles and ages among family caregivers, whether they lived together with the person with dementia or not, and whether they worked. The role, age, and level of dementia of the individuals receiving care also varied.

Five family caregivers participated in one in-depth face-to-face interview lasting $1-1.5$ hours. The first author (geriatric nurse and $\mathrm{PhD}$ fellow) conducted the interviews, which were audio recorded. The interviews took place in the family caregivers' home or at the day care center attended by their relatives. Because the study sought to elicit further knowledge about the positive experiences of family caregivers in the light of their overall situation, the interview guide used focused on three main themes exploring how the family caregivers described, in the past and the present, 1) themselves, their values and goals, and the position they placed themselves into in the caregiving role, 2) their relationship to the person with dementia, and 3) how day care influenced their situation. The interview guide is presented in Table 2.

Inspired by Riessman's understanding of the performative narrative method, we performed a systematic seven-step analysis of each interview. These steps are described in Box 1, and an example of the analysis process (step 5) is described in Box 2 in greater detail.

To ensure the quality of this process, the analysis model was designed under the guidance of two experienced researchers. These two were also involved in the process of selecting key utterances that were descriptive of global, local, and thematic contexts.

During the analysis, themes and quotes were selected and interwoven into a descriptive narrative representing the person's story as a whole. Descriptions of identity, relations, sense of belonging, and so forth were compiled into an overall picture and a descriptive plot based on the researcher's interpretation. These condensed stories were then seen in light of a greater whole, for example, the values of society or attitudes toward dementia or the role of family caregiver. The interviews were conducted and analyzed in Norwegian and then the quotations were translated to English by the research group.

Based on the narrative analyses, the five interviews were transformed into five short narratives summarizing the stories' plots (theme). Each story was given a name. We present the findings as spots on each story's uniqueness and the variation between the stories.

Table I Characteristics of the participants and the persons with dementia

\begin{tabular}{|c|c|c|c|c|c|c|c|}
\hline $\begin{array}{l}\text { Family } \\
\text { caregiver's role }\end{array}$ & $\begin{array}{l}\text { Age of the } \\
\text { family caregiver }\end{array}$ & $\begin{array}{l}\text { Living together } \\
\text { with the person } \\
\text { with dementia }\end{array}$ & Working & $\begin{array}{l}\text { Relationship } \\
\text { of the person } \\
\text { with dementia }\end{array}$ & $\begin{array}{l}\text { Severity of } \\
\text { dementia } \\
\text { (CDR) }\end{array}$ & $\begin{array}{l}\text { Age of the } \\
\text { person with } \\
\text { dementia }\end{array}$ & $\begin{array}{l}\text { Days at day } \\
\text { care (per } \\
\text { week) }\end{array}$ \\
\hline Case I, daughter & 61 & No & Part time & Mother & Mild & 82 & 5 \\
\hline Case 2, son & 54 & No & No & Father & Severe & 76 & 4 \\
\hline Case 3 , wife & 76 & Yes & No & Husband & Moderate & 79 & 4 \\
\hline Case 4 , husband & 79 & Yes & No & Wife & Moderate & 79 & 3 \\
\hline Case 5 , wife & 87 & Yes & No & Husband & Severe & 93 & 3 \\
\hline
\end{tabular}

Abbreviation: CDR, Clinical Dementia Rating Scale. 
Table 2 The interview guide

\begin{tabular}{ll}
\hline Themes/theme areas & Sample question \\
\hline I. Introduction & How are you doing, as a family caregiver? \\
& How has your situation changed lately? \\
2. Relational emotional changes & How do you consider your relationship with your relative? \\
3. Positive experiences in the role & Is there anything about your situation now that you consider to be good? \\
& - What contributes to these good times? \\
& - Why do you think you handle this difficult situation so well? \\
& - What is important in order for you to help and support your relative? \\
& - Is there anything health care workers can do so that you have more good times together? \\
& - What you ever thought that you have to give up or "drop out" of caregiving? \\
& What do you think about taking care of yourself? \\
& - Is it important to prioritize your own needs in your current situation? \\
& - Can you prioritize your own needs or those of others? \\
- Are there any conflicts associated with your needs or those of your relative? & How does your relative attending a day care center impact on your everyday life? \\
& In general, what do you think is important in order for you to do well in your current situation?
\end{tabular}

Note: The interviews were conducted and analyzed in Norwegian and then the quotations were translated to English by the research group.

Box I Narrative step-by-step analysis.

\begin{tabular}{|c|c|}
\hline I. Transcription & From oral speech to text \\
\hline 2. Searching for the narrative's overall theme & What is the core content of the narrative? \\
\hline 3. Organizing the narrative in three main & Identity \\
\hline themes as described by the study & Who am I? \\
\hline \multirow[t]{9}{*}{ objective } & Why am l/are we in this situation? \\
\hline & Are there any conflicts or dilemmas related to who I am and who I want to be? \\
\hline & Relationship \\
\hline & $\begin{array}{l}\text { To whom did I belong? To whom do I belong? How do I experience belonging to a person with } \\
\text { dementia today? }\end{array}$ \\
\hline & Are there any conflicts or dilemmas related to the need of belonging and/or separation? \\
\hline & What position do I take toward the person with dementia? \\
\hline & The influence of day care \\
\hline & How does the day care service influence who I am/who I want to be in this situation? \\
\hline & $\begin{array}{l}\text { How does the day care service influence my needs for belonging/separation/proximity and } \\
\text { distance? }\end{array}$ \\
\hline 4. Searching for the narrative's plot & Write down one or two sentences describing the narrative's plot/main content \\
\hline $\begin{array}{l}\text { 5. Organizing the narrative into meaningful } \\
\text { stories. Analyzing these stories through } \\
\text { questions aimed to concretize and } \\
\text { complement the main themes (point 3) }\end{array}$ & $\begin{array}{l}\text { Ask the questions: } \\
\text { - What is distinctive in the story? } \\
\text { - How is the family caregivers' identity described? } \\
\text { - How is belonging described? } \\
\text { - Are there any conflicts or dilemmas? } \\
\text { - How are their choices of position described? } \\
\text { - How are their stories told? }\end{array}$ \\
\hline $\begin{array}{l}\text { 6. Summing up the analyses of the meaningful } \\
\text { stories in } 5-10 \text { sentences to describe the } \\
\text { condensed content }\end{array}$ & $\begin{array}{l}\text { Are there any repeating themes? } \\
\text { Are there any relationships between the present and past? }\end{array}$ \\
\hline $\begin{array}{l}\text { 7. Write down a short version of the } \\
\text { condensed narrative based on the analyses } \\
\text { and the adjusted plot }\end{array}$ & $\begin{array}{l}\text { The short version of the narrative should give a characteristic view of the family caregiver's } \\
\text { identity, his or her experience of meaning and the relationship to the person with dementia, and } \\
\text { how day care can support him or her to cope }\end{array}$ \\
\hline
\end{tabular}

Note: The interviews were conducted and analyzed in Norwegian and then the quotations were translated to English by the research group.

\section{Findings}

The findings are presented through five narratives describing the family caregivers' individual experiences of meaning in their caring role and how the day care services influenced their experience and motivation in their role.
The condensed narratives are presented and outlined under the following headings:

1. The counselor - from support to emotional closeness.

2. The project leader - from occasional to regular contact. 
Box 2 An example of the analysis process, step 5, narrative one.

Questions I asked the narrative:

- What is distinctive in the story?

- How is the family caregiver's identity described?

- How is belonging described?

- Are there any conflicts or dilemmas?

- How do they describe the position they have chosen?

- How are their stories told?

The plot: the counselor - from support to emotional closeness

The narrative divided into different parts

I am the most caring of us three sisters, the loving one, the one who hugs and touches, who shows an interest in our mother. And that's probably why she says that l'm her favourite in the family. I don't think a mother should say that. You shouldn't even say it even if you have dementia. Before my mother was diagnosed with dementia, she often said "Thank you for your good advice. I should pay you." Sometimes my answers were complicated, but she often said "But I want to hear your opinion because you give good advice." And she seems to have brought this into her dementia - it's there.

When my mother or anyone else visits me, I sit like this. I give my time to whoever is there. I don't do this with my mother all the time now, because it would be tiresome, and things finally go haywire, she talks about the same thing all the time. My solution is to do different things. It's nice when I see that she's happy, and is having a good time. I think I get less irritated now than I did in the past. And I'm a solution-oriented person, my job is to solve problems. So of course, I try to do the same in my private life. I want it to be nice to spend time with her, and for her to be fine when she leaves me; I want her to be left with a good feeling. And I think that that's mostly the case.

I'm my mother's favourite

My mother has always asked for my advice

This is still the case

It's nice that she likes me best, but it isn't good that she says so

I'm important to my mother

I'm sensible when I'm around my mother

I'm solution oriented

I try to do what's best for my mother

I'm fine if she's fine

My mother likes being with me

Note: The interviews were conducted and analyzed in Norwegian and then the quotations were translated to English by the research group.

3. The organizer - from intimacy to routines.

4. The adaptor - from teamwork to solo.

5. The supportive wife - from hanging on to letting him go.

\section{Narrative I: the counselor - from support to emotional closeness}

Mom has always asked me for good advice. When I was in my 20s, she called me daily for support in her difficult relationship with my dad. After my mom got dementia, I found that she became more like a "real mom" for me. Before she got sick, she was concerned only about her own problems, but our relationship has now changed and our closeness has increased; she is more concerned about how I feel. I feel like I understand Mom very well, it is probably because of my education and my strong interest to be with her. Once we lay in the double bed chatting; I felt so close to her - I felt she was a "real mom" for me, interested in my life. Mom likes to participate in day care, it gives her something to do with her days. On those days, I do not need to visit her because her social needs have been met and she has had healthy meals. I think Mom enjoys day care, but there should have been more activities there. When I was on long-term sick leave, I had plenty of time to spend with Mom. Now I am more tired, and therefore, I must give her less priority because I also want to spend time with my boyfriend.
This daughter appreciates the experience shift in the relationship with her mother. As the dementia has progressed, her mother has changed from being a selfish and suffering person to being more interested in her daughter's life. New roles have emerged in the mother-daughter relationship and a new intimacy has developed between them, which the daughter missed earlier. Nevertheless, the daughter still wants to play her old role as her mother's supportive partner. She wants to influence her sisters' caregiving and give them advice, but she feels that they are not particularly receptive to it. Day care keeps the mother active, and this helps the daughter maintain her role without a bad conscience, even though she spends less time with her.

\section{Narrative 2: the project leader - from occasional to regular contact}

Although I am not fond of my father, I feel it is my duty to help him in his current difficult situation. He left our family when I was a teenager; since then, contact has been sporadic. In spite of this, I have no reason to avenge myself on him for what happened to us. I have good relationships with my siblings, and we cooperate well as family caregivers. Dad has given us different roles. He calls me the project leader - it is really a poor job, but I help him when it suits me, so it is fine. Participating in day care gives my father 
rhythm in everyday life, something to regularly attend. He thrives there; he could easily go to day care every day - for the rest of his life. Since he started there, the role as family caregiver no longer affects my daily life. Now I visit him once a week, fix things, and have a cup of coffee. The day care is good for my siblings too, as [our dad] does not nag us as much as he did before he began there. It would not have worked out without day care; otherwise he would have had to move into a nursing home.

This story is about a son's willingness and opportunity to do his duty by helping his father without emotional involvement. He emphasizes that he is not like his father: he does not run away from his responsibilities like his father did. The development of dementia gives him a reason to reconnect with his father and help him, even though he is not fond of him. His father needs him, and he responds to his father's needs by searching for the best in himself. The relational distance helps him set limits for himself and avoid being too emotionally involved. After the father started visiting the day care center, he stopped calling his son at night. That made the son's caregiving role easier and more separate from his daily life.

\section{Narrative 3: the organizer - from intimacy to routines}

I am so dependent on my husband; we have been married for 56 years. For me, there is absolutely no question of sending him to a nursing home, I could not bear to do that. What should I do then? Before, he was so handsome and handy, and now I have to help him with almost everything. At home, I have routines for everything. That is what works for me, but it is very tiring. My "happiness thief" is called stress; I cannot rest or sleep before I have everything under control. Actually, I am a testy person, but now, I have to use a soothing voice, otherwise he gets angry. My husband wants me to lie in his arm as I did before, but now I cannot bear that kind of intimacy. Because of his awkward comments, it is difficult to be social, but we still have some good friends who I can invite, and a neighbor who supports me. Day care gives me time to be with my friends and pay attention to my own needs, and it helps me in my everyday organization. He enjoys himself in day care and on day care days, he gets up, takes a shower, and everything is on schedule. On these days, I am in a good mood as well. I can't make it without day care, but it hurts. I take care of him around the clock, so if we did not have the day care service, I could not have endured the situation. It was not like how it was meant to be. Nevertheless, I need to have him near; it is still the two of us, you know.
This wife struggles with her new role and her new relationship with her husband. They are still a couple, but the relationship has become asymmetric and demanding. To manage, she must change her behavior and stick to strict routines. She is tired of the situation, but she feels she can handle it, largely because of the day care service. Without day care, she is not able to keep the two of them together the way she wants.

\section{Narrative 4: the adaptor - from teamwork to solo}

My wife and I have moved several times because of my job. Hence, we have always been close and quick in adapting to new places and making new friends. Because of my wife's sickness, now I have to adapt our social life to her needs. That is ok, because I am a good cook, so we still often invite family and friends for dinner or coffee. If we are invited to friends' homes, I have to make sure that she gets rest, and I give her an extra tablet so she can stand it a little bit longer. However, when she has her anxiety attacks, it is hard to handle. We are coping with our everyday life, but when she starts with her meaningless activities, for example, washing the floors repeatedly, we often end up arguing. When I ask her to stop, it provokes confrontations and I feel helpless. My wife is attending a day care center, this gives me free time and time for rest. People tell me that I have a hard job with my wife, but I think it is fine. As long [as] she is participating [in] day care, and the situation does not get worse, I can adapt to our new situation.

This husband works hard to adapt to their new situation and maintain their social network. Even though he thinks dementia is challenging, their friends and their social life provide links to their "normal life": a life which this husband is trying to hold on to. The activities he describes as meaningless irritate him and make him feel out of control and angry. This is hard for both of them. On day care days, they spend several hours apart, and this makes him more patient in the relationship.

\section{Narrative 5: the supportive wife - from hanging on to letting go}

We have been married for over 60 years, and we have always been together. I was in charge of his company and he was very dependent on me. Now his dementia is severe, so I have to look after him constantly. God helps me, but now it is very hard because of my own health problems. It is 
like looking after a baby; the roles are completely changed, and he speaks very little. When my husband is at day care, I can go shopping or for a cup of coffee with my nieces. I really enjoy these moments. In addition to day care, I have regular respite when he is in the nursing home. Then, I can sleep during the whole night and I do not have to rush. I relax when he is away, but I also feel guilty because I have "sent him away". When he is at day care, I feel no guilt the way I do when he stays at the nursing home. Our sons are supporting me; they say it is too hard for me to care for him at home. The staff at the day care service also tell me so. I know I will be fine if he moves to a nursing home, but I am afraid that he will feel abandoned.

This wife struggles with two conflicting feelings. On one hand, she wants her husband to stay at home, but on the other hand, she has to accept letting him go. This is a difficult process for her, and she seeks arguments and support to justify her feelings and her choices. Living separately seems to make life easier, but the risk that her husband will feel abandoned makes her insecure and vulnerable in this decision-making process. The husband's participation in day care gives the wife less feelings of guilt than when she "sent him" to the nursing home for relief. Although using day care as a respite service is the best option for her, she is extremely tired and is in need of more respite than the day care can offer.

\section{Discussion}

The aim of this study was to gain knowledge about meaning in the family caring role, and how day care services may influence family caregivers' experience and motivation in this role. According to Folkman, meaning-focused coping creates the opportunity for a person to act in accordance with their values and goals. ${ }^{10}$ The five narratives present a picture of how family caregivers cope with their new situation in different meaningful ways. These results are discussed in relation to three main themes:

1. enhancing, maintaining, or letting go of relational ties;

2. finding a balance between caring for one's own and another's needs;

3. increasing family caregivers' motivation to care with the help of day care.

\section{Enhancing, maintaining, or letting go of relational ties}

The family caregivers' descriptions incorporate a variety of strategies they use to cope with their relational ties. Should they maintain and strengthen their emotional relationship with the person with dementia or let it go? They describe different relational and emotional coping strategies ranging from a desire for emotional closeness and a need to hold on to the connection to the need for distance and acknowledging the need to gradually let the relationship go.

According to the daughter in narrative 1, the new situation gives her an opportunity to fulfill her need for emotional closeness to her mother. She likes her position as her mother's closest daughter and she seeks appreciation from her mother - as she always has done. The new intimacy motivates her to act in accordance with her values, which include being a good caregiver for her mother. By doing so, she simultaneously satisfies her own need for emotional closeness.

The son in narrative 2 feels a sense of duty to provide care for his father despite the emotional distance between them a distance he describes as expedient and rational in his role as caregiver. This duty includes supporting and helping his father without taking revenge for the betrayal by his father he experienced earlier in his life. The emotional distance makes it easier to limit his involvement while at the same time do his duty in accordance with his own values. This son meets his obligations as expected by the community and receives gratitude from his father.

The spouses in this study describe different relational changes. The wife in narrative 3 struggles to maintain emotional closeness to her husband. Her primary goal is to stay together with her husband in the marriage. This goal motivates her to care for him even if she is stressed and tired. She describes a potential situation without this caregiving role as empty, lonely, and meaningless. The wife wants to fight for her strong relationship with her husband. She still values this relationship highly, even though it has significantly changed because of her husband's dementia. To handle her challenges, she implements a daily schedule to fulfill her need for predictability and control. That schedule helps her in her role as family caregiver and brings their life under control. Similarly, the husband in narrative 4 introduces stricter routines and control for the purpose of maintaining the relationship. By doing so, he intends to maintain their social network. He fulfills his need for a social network by taking responsibility for the housekeeping and invitations to social events.

Regarding the wife in narrative 5, the relational emotional challenge is connected to the hard process of "letting go." She knows that she must loosen her emotional ties to her husband. This is painful because "staying together" is one of the things she values most. This process brings forth ambivalent feelings: she wants to remain close to her husband, 
but she is very tired and longs for freedom and time to meet her own needs. In this process, she becomes sad when she dwells on the possibility that their long cohabitation could end. When she has to entrust her husband to professional health care workers, her relational focus changes from "staying together" to "fixing their lives separately." In this process, she needs acceptance and support from family members and health care workers at the day care center. According to Molyneaux et al, this shift in focus is expedient in reducing the family caregiver's burden. ${ }^{13}$ However, this wife describes this experience as painful.

These five narratives demonstrate in various ways how meaningful relationships motivate family caregivers to act in accordance with their own values and goals. These results confirm the "relationship-oriented coping" theory" and previous research describing how family caregivers find meaning in their role. ${ }^{5,10}$

All the family caregivers feel that the day care center positively influences the relationship between themselves and the person with dementia. Attendance at day care provides individuals with dementia with topics to discuss later with the family caregiver, and they are calmer and more satisfied on the days they attend day care. This leads to less nagging and conflicts between them and their caregivers. Hence, day care has a positive influence on the ability of family caregivers to cope in the caregiving role.

\section{Finding a good balance between caring for one's own and another's needs}

The family caregivers describe challenges connected to finding a balance between maintaining the needs of the person with dementia and taking care of their own needs. This dilemma can be elucidated by the ideal of altruistic care that influences the community and affects the family caregiver's own expectations and demands in their role as caregivers.

The Norwegian philosopher Pettersen criticizes the ideal of the altruistic, compassionate caregiver, ${ }^{26}$ which has been the prevailing caregiving ideal throughout human history. Altruistic care is meant to be selfless and should be unconditionally based on spontaneous compassion and sacrifice. The altruistic care ideal can disallow caregivers' needs, including the need for support and relief. In altruistic care philosophy, the caregivers' feeling of doing the "right thing" is both their reward and their motivation for caring or doing their duty. This means putting their own needs aside in favor of another persons' needs. ${ }^{26}$

Duty is a prominent motivator for family caregivers. However, how this value is expressed and justified varies. The wives' stories reflect their feelings of marital duty based on their own expectations of being supportive and the desire to preserve the emotional closeness in their relationships with their husbands. The son justifies his sense of duty based on values from his childhood inherited from his mother and grandparents. The emotional distance that he has from his father helps him balance his own needs with those of his father in an expedient way. Placing emotional limits on caregiving helps the son provide so-called mature care. Mature care is a care philosophy meant to conceptualize care as a rational, not a monodirectional activity. In this conception of care, self-care is not by definition unethical, but a prerequisite part of ethical care. ${ }^{26}$

The daughter in narrative 1 is motivated by her own needs for intimacy with her mother. The combination of her own and her mother's needs must be made visible and reflected in the caregiving role. According to mature care philosophy, regular reflection about the situation can increase the caregiver's understanding of their role as caregiver and the care recipient's needs. Reflection might lead to new understanding and help the caregiver balance his or her needs with those of the care recipient. If the caregiver's primary need is intimacy, the caregiver might take advantage of the situation. If meeting the needs of the caregiver is the main option, the person with dementia could suffer because of their total dependency on the caregiver and their limited ability to leave the relationship. However, the mutual need for satisfaction could balance the relationship.

According to mature care philosophy, the caregiver and the care receiver's needs, interests, and values are equivalent. Hence, this philosophy violates the traditional altruistic care ideal, as it is based on communication between equal partners, information, expertise, and continuous reflection. According to mature care philosophy, it is immoral to put one's own values and needs as caregiver aside, at least over time. ${ }^{26}$

The mature care philosophy criticizes the altruistic care ideal based on the risk of negative consequences for both the caregiver and the care recipient. The family caregivers, particularly the spouses, describe how they prioritize the needs of the person with dementia over their own. They try to balance their own needs and the needs of the person with dementia, and hence maintain equal roles.

According to Pozzebon et al, the process of losing a partner with dementia can be broken down into four phases: 1) acknowledging change, 2) being in crisis, 3) adapting and adjusting, and 4) accepting and moving forward. ${ }^{27}$ The wives in the current study describe their situation according to 
these phases. They alternate between adapting the situation by following strict routines and trying to accept more help from professional health workers. Their shifting emotions include thankfulness, love, happiness, anger, powerlessness, and despair. Both women try to spare their husbands from experiencing their negative feelings. Being angry or sad gives them both a bad conscience. To cope with everyday life, regular morning and afternoon routines are crucial for the wife in narrative 3 . Having these routines fulfills her need for control and mastery of the situation.

This study reveals that family caregivers have more time to attend to their own needs when the person with dementia attends day care. According to the mature care philosophy, day care increases family caregivers' opportunities to maintain a balanced relationship with the person with dementia. In all stages of dementia, support from day care staff is important to relieve family caregivers from feelings of bad conscience as they seek to meet their own needs. This is especially important in situations where they have to consider the need for home care or institutional services. In these situations, family caregivers need to be supported to be able to redefine their values and goals and to adapt to a new or adjusted "meaning focus" in their caregiving role.

\section{Increasing family caregivers' motivation to care with the help of day care}

The family caregivers describe the relationships with the person with dementia as essential in their motivation for caregiving. According to the motivation theory, we are guided by our motivation when acting and making choices. ${ }^{28,29}$ Motivation is linked to the extent to which our actions will lead us to our desired outcomes and goals. Additionally, it refers to the processes that lead to the achievement of the goal.

The motivation to act can be intrinsic and/or extrinsic. Intrinsic motivation refers to initiating an activity for its own sake because it is interesting and satisfying in itself, as opposed to doing an activity to obtain an external goal (extrinsic motivation). In their theory of self-determination (SDT), Deci and Ryan focus on the differences between intrinsic and extrinsic motivation and describe three psychological needs that motivate the self to initiate behaviors that are essential for psychological health and well-being. ${ }^{30}$ Competence refers to the perception that one's behavior results in the intended outcomes and effects. Relatedness refers to feeling connected to others and the capacity to receive feedback from them. Autonomy refers to being able to choose activities, make decisions, and regulate behavior in accordance with one's goals. ${ }^{31,32}$
According to this theory, support and relief from day care have the potential to enhance family caregivers' motivation to care. The family caregivers' competence is important. It is important for them to be able to choose the actions that are necessary to achieve their value-based goals of caregiving. As previously described, respite gives family caregivers more energy and patience in their complex caregiver role. They become more competent as caregivers. In addition to providing respite, the day care staff has the possibility to offer support and guidance to family caregivers, assuming that the staff has knowledge about the caregivers' values and their goals for caregiving. In Norway, the municipalities offer classes for family caregivers where they receive information about the health care system and their rights and learn about dementia and communications skills. Additionally, caregivers are offered support groups run by trained health professionals. Individual guidance from day care staff could be a complementary supplement to the classes for family caregivers. The staff's competence in dementia care makes them especially skilled to give individual support and advice to family caregivers.

According to the mature care philosophy, using day care as a respite and support service can increase family caregivers' autonomy and ability to meet their own needs; this was described by the participants in the study. The support from day care staff is central to caregivers' ability to make autonomous choices and maintain these choices. The staff has to respect family caregivers' various choices in their care provision and empower them to act in accordance with their own values.

According to SDT, the relationship between the person who provides support and the person who receives support is an essential effective factor. Therefore, the staff must be emphatic and know the family caregivers' individual situations when offering them support.

The family caregivers describe how their feeling of duty affects their actions in different ways and with varying strength. This feeling of duty is related not only to their personal values but also to the values and expectations of society. Through this feeling of duty, the family caregivers describe how the aim of the action motivates them to care (extrinsic motivation) more than the action itself (intrinsic motivation). As per the SDT, the activities motivated by intrinsic motivation are activities or situations in which the activities themselves are the primary motivating factor. The family caregivers describe how day care enhances their chances of having several good moments together with the person with dementia, for example, having a pleasant telephone call, a 
nice meal, or emotional intimacy. Based on the family caregivers' descriptions, day care, as a support and relief service, can contribute to facilitating intrinsic motivation in family caregivers. Activities based on intrinsic motivation are more rooted in the integrity of the person than are activities based on extrinsic motivation. Furthermore, activities rooted in a person's integrity have a higher potential to increase that person's psychological health and well-being. ${ }^{30}$

\section{Methodological considerations}

The in-depth semi-structured interviews provided a rich source of material with personal descriptions related to the aim of this study. The participants were diverse with respect to gender, age, and caregiver roles (spouses or children living together or separately), and the sample included caregivers of people with various degrees of dementia. Considering the aim of the study, the narrative method was appropriate because it provides relevant knowledge about the participants' experiences of meaning based on their values, goals, and relationships.

This study has some limitations. Only one interview was carried out with each participant, and hence, it was not possible to verify the researchers' interpretations of the data or for the participants to add further information. Had we used a longitudinal approach with repeated interviews, the study could have provided greater insight into how the caregiver role changes as the disease progresses. Although the results cannot be generalized to other groups of caregivers, they can elucidate the situations of similar groups of family caregivers and how their needs for support and respite can be met.

\section{Conclusion}

This study reveals that finding meaning in the role of family caregiver for persons with dementia is closely connected to the caregivers' own values and goals. Finding a balance between attending to their own needs and the needs of the person with dementia is crucial. To accomplish this, individual support can be useful, for example, individual tutorials with day care staff who know the person with dementia well. Day care has the potential to increase family caregivers' motivation to care by supporting their capacity to meet their own needs, cooperate and communicate with the person with dementia, and make competent and autonomous choices, thus increasing their sense of mastery.

\section{Acknowledgment}

The study was funded by the Research Council of Norway.

\section{Disclosure}

The authors report no conflicts of interest in this work.

\section{References}

1. Huang SS, Lee MC, Liao YC, Wang WF, Lai TJ. Caregiver burden associated with behavioral and psychological symptoms of dementia (BPSD) in Taiwanese elderly. Arch Gerontol Geriatr. 2012;55(1):55-59.

2. WHO. Mental health and older adults fact sheet. 2016. Available from: http://www.who.int/mediacentre/factsheets/fs381/en/. Accessed November 27, 2017.

3. Pearlin L, Mullan JT, Semple SJ, Skaff MM. Caregiving and the stress process; an overview of concepts and theirs measures. Gerontologist. 1990;30:583-591

4. Balla S, Simoncini M, Giacometti I, Magnano A, Leotta D, Pernigotti LM. The daily center care on impact of family burden. Arch Gerontol Geriatr. 2007;44(Suppl 1):55-59.

5. Zarit SH. Positive aspects of caregiving: more than looking on the bright side. Aging Ment Health. 2012;16(6):673-674.

6. Tarlow BJ, Wisniewski SR, Belle SH, Rubert M, Ory MG, GallangherThompson D. Positive aspects of caregiving. Contributions of the REACH project to the development of new measures for Alzheimer's caregiving. Res Aging. 2004;26(4):429-453.

7. Folkman S. Positive psychological states and coping with severe stress. Soc Sci Med. 1997;45:1207-1221.

8. Lazarus RS, Folkman S. Stress, Appraisal, and Coping. New York: Springer; 1984.

9. Park CL, Folkman S. Meaning in the context of stress and coping. Rev Gen Psychol. 2007;2:115-144.

10. Folkman S. The case for positive emotions in the stress process. Anxiety Stress Coping. 2007;21:3-14.

11. Ingebretsen R. Ansatte i demensomsorgen - på jobb og i relasjoner [Employees in dementia care - at work and in relationships]. Aldring og livsløp. 2006;3:8-13. Norwegian.

12. Ingebretsen R, Solem PE. Aldersdemens i parforhold [Dementia in marital relationships]. Oslo: Norsk institutt for forsking om oppvekst, velferd og aldring; 2002. Norwegian.

13. Molyneaux VJ, Butchard S, Simpson J, Murray C. The co-construction of couplehood in dementia. Dementia. 2011;11:482-502.

14. Eek A, Nygård AAM. Lysning i sikte? Tilbud til personer med demens i norske kommuner. Landsdekkende undersøkelser [Lighting in sight? Offers for people with dementia in Norwegian municipalities. National surveys]. Tønsberg/Oslo: Forlaget Aldring og helse; 2006. Norwegian.

15. Westerberg TH, editor. Gode tilbud i demensomsorgen - demensteam, dagsenter og pårørendeskoler. Kartlegging 2007 [Offers with hight quality - dementia team, day care centers and classes for relatives. An overview from 2017]. Tønsberg: Forlaget Aldring og helse; 2009. Norwegian.

16. Ministry of Health and Care Services. Dementia Plan 2020. Oslo: Ministry of Health and Care Services; 2007.

17. Gjøra L, Eek A, Kirkevold Ø. Nasjonal kartlegging av tilbudet til personer med demens 2014. Demensplan 2015 [National survey of the offer to people with dementia 2014. Dementia plan 2015]. Tønsberg: Nasjonal kompetansetjeneste for Aldring og helse; 2015. Norwegian.

18. Tretteteig S, Vatne S, Rokstad AMM. The influence of day care centres for people with dementia on family caregivers: an integrative review of the literature. Aging Ment Health. 2016;20(5):450-462.

19. Tretteteig S, Vatne S, Rokstad AMM. The influence of day care centers designed for people with dementia on family caregivers - a qualitative study. BMC Geriatr. 2017;17:5.

20. Riessman CK. Narrative Analysis. Newbury Park, CA: Sage; 1993.

21. Fossland T, Thorsen K. Livshistorier i teori og praksis [Life stories in theory and practice]. Bergen: Fagbokforlaget; 2010. Danish.

22. Riessman CK. Narrative Methods for the Human Sciences. Los Angeles: Sage Publications; 2008. 
23. Riessman CK. Performing identities in illness narrative: masculinity and multiple sclerosis. Qual Res. 2003;3(1):5-33.

24. Riessman CK. Narrative analysis. In: Kelly N, Horrocks C, Milnes K, Brian R, Robinson D, editors. Narrative, Memory \& Everyday Life. Huddersfield: University of Huddersfield; 2005:1-7.

25. Rokstad AM, Halse I, Tretteteig S, et al. Effects and costs of a day care centre program designed for people with dementia - a 24 month controlled study. J Clin Trials. 2014;4(4).

26. Pettersen T. Conceptions of care: altruism, feminism and mature care. Hypatia. 2012;27(2):366-389.

27. Pozzebon M, Douglas J, Ames D. Spouses' experience of living with a partner diagnosed with a dementia: a synthesis of the qualitative research. Int Psychogeriatr. 2016;28(4):537-556.
28. Lewin K. Principles of Topological Psychology. New York: McGrawHill; 1936.

29. Tolman EC. Purposive Behavior in Animals and Men. New York: Century; 1932.

30. Deci L, Ryan RM. The "what" and "why" of goal pursuits: human needs and the self-determination of behavior. Psychol Inq. 2000;11(4):227-268.

31. Ryan RM, Deci EL. Overview of self-determination theory: an organismic dialectical perspective. In: Deci EL, Ryan RM, editors. Handbook of Self-Determination Research. Rochester: The University of Rochester Press; 2002:3-33.

32. Custers AF, Westerhof GJ, Kuin Y, Riksen-Walraven M. Need fulfillment in caring relationships: its relation with well-being of residents in somatic nursing homes. Aging Ment Health. 2010;14(6):731-739.
Journal of Multidisciplinary Healthcare

\section{Publish your work in this journal}

The Journal of Multidisciplinary Healthcare is an international, peerreviewed open-access journal that aims to represent and publish research in healthcare areas delivered by practitioners of different disciplines. This includes studies and reviews conducted by multidisciplinary teams as well as research which evaluates the results or conduct of such teams or health

\section{Dovepress}

care processes in general. The journal covers a very wide range of areas and welcomes submissions from practitioners at all levels, from all over the world. The manuscript management system is completely online and includes a very quick and fair peer-review system. Visit http://www.dovepress.com/ testimonials.php to read real quotes from published authors.

Submit your manuscript here: https://www.dovepress.com/journal-of-multidisciplinary-healthcare-journal 